\title{
Adverse effects and temporomandibular joint disorder associated with Khat chewing: a prospective study.
}

\author{
Waleed Saeed Bakhadher ${ }^{1}$, Saeed Bajafar ${ }^{2}$, Dhfer Alshayban ${ }^{3}$, Ibrahim Sales ${ }^{4}$, Yaser Mohammed \\ AlWorafi $^{5}$, Syed Wajid ${ }^{4}$, Salmeen Babelghaith ${ }^{4}$, Mansour Adam Mahmoud ${ }^{6 *}$ \\ ${ }^{1}$ Associtae Consultant in Orthodontist, Private Practice, Makkah, Saudi Arabia \\ ${ }^{2}$ Department of Pedontics and Preventive Dentistry, Ain Shams University, Cairo, Egypt \\ ${ }^{3}$ Imam Abdulrahaman Bin Faisal University, College of Clinical Pharmacy, Damam, Saudi Arabia \\ ${ }^{4}$ Clinical Pharmacy Department, College of Pharmacy, King Saud University, Riyadh, Saudi Arabia \\ ${ }^{5}$ Department of Clinical Pharmacy, College of Pharmacy and Health Sciences, Ajman, United Arab Emirates \\ ${ }^{6}$ Taibah University, Clinical and Hospital Pharmacy Department, College of Pharmacy, AL-Madinah Al-Munawara, \\ Saudi Arabia
}

\begin{abstract}
Background: Khat (Catha edulis) is a plant with its leaves containing alkaloids similar to caffeine that provides pleasurable and mildly stimulating effects. Prolonged use of Khat is associated with mental health disturbances and may cause severe damage to the temporomandibular joint.

Objectives: The objective of this study was to assess the effects of Khat on oral health among Khat chewers in the city of Aden, Yemen.

Methodology: A prospective study was carried out among Khat chewers in Aden, Yemen, between October 2013-October 2015. A survey questionnaire was developed and distributed among Khat users to explore various aspects related to oral health. Statistical analysis was performed using SPSS version 22.0. P-values of less than 0.05 were considered significant.

Results: 240 Khat users participated in the survey. Khat chewing was associated with many side effects. The most common side effects were pain, a clicking sound during opening and closing of mouth, tonicity, loss of teeth, and occlusion. The occurrence of temporomandibular joint disorder (TMJD) disorders was higher with those chewing Khat alone (34.2\%) than those chewing Khat and other items such as betel nuts $(14.6 \%)$ and tombol $(13.4 \%)$. The incidence of TMJD was more in the age range of 15-25 $y$ compared to those in other age groups $(\mathrm{P}=0.036)$ and in those chewing $K$ hat $>5$ days a week $(P=0.029)$.

Conclusion: A significant number of Khat users are affected by TMJD. This public health hazard poses an additional danger to an already substantial list of severe health concerns related to Khat chewing.
\end{abstract}

Keywords: Adverse effects, Temporomandibular joint disorder, Khat, Prospective study.

Accepted on November 28, 2018

\section{Introduction}

Qat or Khat (Catha edulis) is a flowering plant primarily in Eastern Africa and in parts of the Arabian Peninsula known for its stimulating and euphoric effects. Chewing of leaves of this plant is a common practice in this region. Currently, this practice is rapidly spreading in North America and Europe through emigrants and refugees from Yemen, Somalia, and Ethiopia [1]. Evaluation of microsatellites of Khat shows that it contains two amphetamines which are considered controlled substances in many countries, cathinone (Schedule I) and cathine (Schedule IV), and falls under the rules and regulations of a controlled substance in many counties [2]. The phenylalkylamines and cathedulins are the major alkaloids which are structurally related to amphetamine. Chewing Khat leaves releases cathinone, a stimulant that produces a feeling of euphoria, causes users to feel more alert and sociable, and suppresses the appetite [3]. The numerous health problems associated with Khat are not only caused by chewing the leaves, but also due to the fact that the plant is predominantly heavily laced with chemical pesticides such as dimethoate [4].

The history of Khat chewing in Yemen dates to the pre-Islamic Era, and now it is commercially cultivated in the mountains of Sanaa and Taiz. Various studies conducted in Yemen have shown that nearly $90 \%$ of the population including medical 
students in Aden University are addicted to Khat, although it is classified as "drug of abuse" by the World Health Organisation (WHO) [5,6]. Khat chewing has recently become common among pregnant women in Yemen with approximately $41 \%$ reporting prenatal use. In previous decades, Khat chewing by women and children was considered unacceptable, but recently, its use among these populations has increased and become more socially acceptable [7].

A large number of the population in Jazan, located in the southern province of Saudi Arabia and shares a border with Yemen, are also active Khat chewers. However, unlike Yemen, the impact of peer pressure is higher among male users than females [8,9]. A study conducted among the students in Jazan reported that the majority of those who chewed Khat were also smokers and that Khat chewing placed its users at a high risk for poor academic performance [10].

Various studies conducted among Khat users show that there is an element of cultural identity and a mistaken social role attached with this practice which is magnified in light of the appalling state of unemployment in the country [11-13]. Khat distributors and sellers are also making use of these sentiments while grossly violating the general trade standards and regulations. They justify this abomination by claiming to be providing a community service by creating an environment for social interaction among their customers [14].

The habit of Khat chewing affects the systemic and oral health by severely altering the phenotype and function of immune cells [15]. Generally, the Khat leaves are placed in the mouth in the lower distal mucobuccal fold creating a noticeable pouch. Furthermore, the leaves are chewed for a lengthy amount of time which causes loss of periodontal attachment and presents either as an increased pocket depth or gingival recession. The mechanical and chemical irritation in the oral cavity later develops into mucosal white lesions and dark pigmentation [16]. Although Khat chewing may reduce the risk of gingival and periodontal inflammation, it appears to encourage attachment loss at the site of chewing [17].

There is a paucity of literature regarding the association between Khat chewing and TMJD. The objective of this study was to assess the effects of Khat on oral health among Khat chewers in the city of Aden, Yemen.

\section{Materials and Method}

\section{Study design}

A prospective study was carried out among Khat chewers in Aden, Yemen, between October 2013-October 2015. The first part of the study consisted of designing, developing, and pilot testing the questionnaire based on content validity, and pretesting among ten respondents randomly selected from the study participants.

\section{Study population}

A convenient sampling technique was utilized. A sample of 240 active Khat chewers (205 male and 35 females) was selected from different locations in Aden.

\section{Study instrument}

Demographic details of the respondents were gathered along with other specific questions through a questionnaire developed to collect adverse reaction information related to Khat chewing.

\section{Inclusion and exclusion criteria}

Active and consenting Khat chewers were included in the study. Exclusion criteria included subjects who were suffering from systematic illnesses and non-Khat chewers. Each individual completed a medical and dental history and signed an informed consent form. All participants accepted oral examination in a room exposed to direct sunlight and each one answered the questionnaire investigating various aspects related to their oral health and chewing habits. The study protocol was approved by the Research and Ethics Committee at faculty of dentistry, Aden University.

\section{Data analysis}

The completed data were entered into Statistical Package for the Social Sciences (SPSS) version 22 software (SPSS Inc., Chicago, IL, SA). Descriptive statistics including percentages and frequency distribution was applied. Chi-square test and fishers exact test were used as appropriate.

\section{Results}

\section{Demographic characteristics and duration of Khat use}

Majority of the participants were male $(85.4 \%)$ and in the age group 15-25 y old (Table 1).

Most of the participants (35.8\%) used Khat for 1-10 y, 28.7\% used Khat for 11-20 y and 27.5\% used Khat for a period of 21-302 y. The majority of the participants (60.4\%) reported that the amount of time spent on Khat chewing was $>5 \mathrm{~h}$ a day, $81.3 \%$ reported chewing Khat once a day, and 50\% chewed Khat $>5 \mathrm{~d}$ a week (Table 1 ).

\section{Adverse effects related to Khat chewing}

The most common side effect associated with Khat chewing was attrition (70\%) followed by a clicking sound during the opening and closing of the jaw (57\%), abnormal occlusion $(56.3 \%)$, and having restored teeth $(45.8 \%)$. Less than half $(42.5 \%)$ of the participants reported that they felt oral pain and $42.1 \%$ had lost teeth. Erosion was reported by $35 \%$ and $15 \%$ had trouble during chewing (Figure 1). 


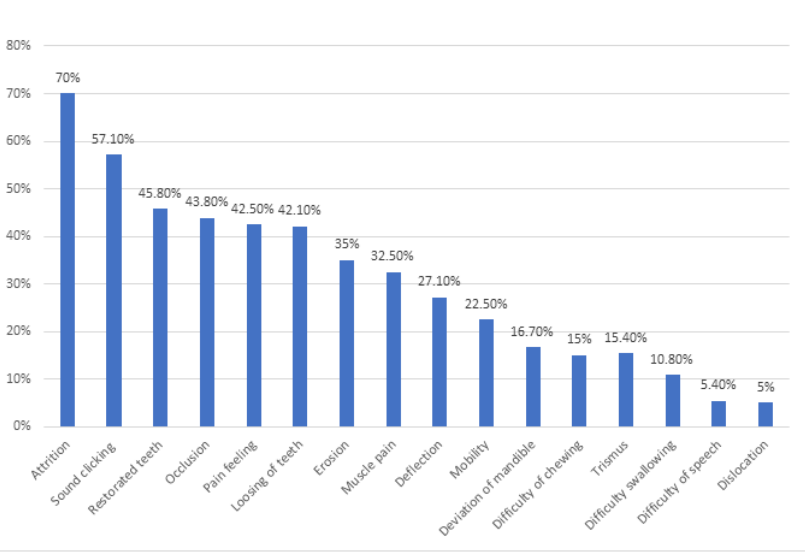

Figure 1. Adverse effects of Khat chewing.

\section{Prevalence of TMJ among Khat chewers}

Of the respondents $34.2 \%$ reported having TMJD, and Khat chewing was the primary cause. The prevalence of TMJD was higher in those who used Khat alone (34.2\%) than those chewing Khat and other items such as betel nuts $(14.6 \%)$ and tombol (13.4\%) (Table 2).

\section{Association of TMJ with demographic characteristics}

Khat use was significantly associated with TMJ users in the age group $15-25(\mathrm{p}=0.036)$ and Khat use $>5 \mathrm{~d}$ a week $(\mathrm{p}=0.029)$ (Table 3).

Table 1. Demographic characteristics and duration of Khat use.

\begin{tabular}{|c|c|c|}
\hline Age & Frequency & $\%$ \\
\hline $15-25$ y & 86 & 35.8 \\
\hline $26-35$ y & 45 & 18.8 \\
\hline $36-45$ y & 37 & 15.4 \\
\hline $46-55$ y & 52 & 21.7 \\
\hline$>55$ y & 20 & 8.3 \\
\hline \multicolumn{3}{|l|}{ Gender } \\
\hline Male & 205 & 85.4 \\
\hline Female & 35 & 14.6 \\
\hline \multicolumn{3}{|c|}{ Duration of Khat chewing } \\
\hline $1-10 y$ & 86 & 35.8 \\
\hline $11-20 y$ & 69 & 28.7 \\
\hline $21-30 y$ & 66 & 27.5 \\
\hline$>30 y$ & 19 & 7.9 \\
\hline \multicolumn{3}{|c|}{ Time spent on Khat chewing } \\
\hline $1-2 \mathrm{~h}$ & 20 & 8.3 \\
\hline $3-4 \mathrm{~h}$ & 75 & 31.3 \\
\hline$>5 \mathrm{~h}$ & 145 & 60.4 \\
\hline
\end{tabular}

\begin{tabular}{lcc}
\hline Frequency of Khat chewing during a day & & \\
\hline Once & 195 & 81.3 \\
\hline Twice & 35 & 14.6 \\
\hline$>3$ times & 10 & 4.2 \\
\hline How many times do you chew Khat in a week? & & \\
\hline 1-2 d & 53 & 22.1 \\
\hline 3-4 d & 67 & 27.9 \\
\hline$>5$ d & 120 & 50 \\
\hline Side of Khat chewing & & \\
\hline Right & 73 & 30.4 \\
\hline Left & 116 & 48.3 \\
\hline Alternately & 51 & 21.3 \\
\hline
\end{tabular}

Table 2. Prevalence of TMJ among Khat chewers.

\begin{tabular}{lll}
\hline & \multicolumn{1}{l}{ TMJD } \\
\cline { 2 - 3 } & Yes & No \\
\hline Khat chewers & $82(34.2 \%)$ & $158(65.8 \%)$ \\
\hline Yes & 0 & 0 \\
\hline No & & \\
\hline Khat plus tombol & $11(13.4 \%)$ & $24(15.2 \%)$ \\
\hline Yes & $71(86.6 \%)$ & $134(84.8 \%)$ \\
\hline No & $12(14.6 \%)$ & $13(8.2 \%)$ \\
\hline Khat plus Betel nut & $70(85.4 \%)$ & $145(91.8 \%)$ \\
\hline Yes &
\end{tabular}

Table 3. Association of temporomandibular joint disorder among Khat users with demographic characteristics and frequency and duration of Khat use.

\begin{tabular}{|c|c|c|c|}
\hline & \multicolumn{2}{|l|}{ TMJD } & \multirow[t]{3}{*}{ P value ${ }^{*}$} \\
\hline & Yes & No & \\
\hline & N (\%) & N (\%) & \\
\hline Gender & & & 0.431 \\
\hline Male & $68(82.9)$ & $137(86.7)$ & \\
\hline Female & $14(17.1)$ & $21(13.3)$ & \\
\hline Age (y) & & & 0.036 \\
\hline $15-25$ & $26(31.7)$ & $60(38)$ & \\
\hline $26-35$ & $16(19.5)$ & $29(18.4)$ & \\
\hline $36-45$ & $20(24.4)$ & $17(10.8)$ & \\
\hline $46-55$ & $12(14.6)$ & $40(25.3)$ & \\
\hline$>55$ & $8(9.8)$ & $12(7.6)$ & \\
\hline
\end{tabular}




\begin{tabular}{llll}
\hline $\begin{array}{l}\text { How many times do you chew Khat in a } \\
\text { week }\end{array}$ & & & \\
\hline $1-2 \mathrm{~d}$ & $1(8.3 \%)$ & $6(42.9 \%)$ & 0.029 \\
\hline $3-4 \mathrm{~d}$ & $2(16.75)$ & $2(14.3 \%)$ & \\
\hline$>5 \mathrm{~d}$ & $9(75 \%)$ & $6(42.9 \%)$ &
\end{tabular}

\section{Discussion}

This study aimed to investigate the adverse effects and prevalence of TMJ related to Khat chewing among Khat chewers in the city of Aden, Yemen. Majority of the participants were males similar to previous studies reporting a higher prevalence of Khat chewing among males as opposed to females $[18,19]$. The onset of developing psycho-stimulation effects such as euphoria and excitement vary among individuals. Previous study reported that the durations of Khat chewing varies between short periods of time to over 30 years [20]. In the current study it was found that most participants reported that they have used Khat for 1-10 years. In addition, the amount of time spent chewing Khat in the current study was $>5 \mathrm{~h}$ a day. This result is consistent with another study which suggested that Khat is often chewed for a period of more than five hours [10]. A large proportion of current Khat users $(81.3 \%)$ reported that they use it once a day for more than $5 \mathrm{~d}$ per week. This result differs from a study by Al-Sanosy which estimated that many users chewed Khat 2-3 times a week [10]. However, the study targeted only students, while our study sample included the public.

Khat chewing may have numerous potentially harmful adverse effects [21]. These side effects range from mild to serious. Our study found that attrition, the clicking sound during opening and closing the jaw, abnormal occlusion, and having restored teeth were among the most common side effects of Khat chewing. These results are consistent with the finding of a review that ascertained Khat chewing as a cause of emotional instability and irritability [22]. The same review also established that Khat use is associated with potentially significant toxic effects including impaired cognitive functioning, insomnia, anxiety, psychotic reactions, hypnagogic hallucinations, bronchitis, tachypnea, polydipsia, chronic gastritis, gastric ulcer, constipation, anorexia, weight loss, cirrhosis, urinary retention, impotence, tachycardia, arrhythmia, hypertension, vasoconstriction, and myocardial infarction [22].

Our results showed that approximately one third of the participants had TMJD and that Khat chewing was the primary cause. The pain usually originates from TMJ and masticatory muscle dysfunction [23]. Similar to our study findings, a study in the late eighties reported that Khat chewing was associated TMJ with clicking and pain and that a positive correlation existed between the intensity of symptoms and the frequency and duration of Khat chewing [24]. According to the National Institute of Dental and Craniofacial Research, the prevalence of TMJD is between 5\% and 12\%. More specifically, the prevalence rates of TMJ disorders are higher among younger persons. This result is not similar to our findings where TMJD were found to be more among participants aged 30-45 y. This could possibly be because of the smaller sample size in the current study, because our study was not a national study.

With respect to gender, our study reported that TMJD is more prevalent in men than women. However, this conflicts with the same report from the National Institute of Dental and Craniofacial Research which stated that TMJD are at least twice as prevalent in women as men [25]. Another study conducted among university students in Yemen Also reported high prevalence of Khat chewing among females [26]. In addition, our results revealed that chewing Khat more than $5 \mathrm{~d}$ per week was significantly associated with the incidence of TMJD. Our study is limited by the lower number of females due to cultural barriers.

\section{Conclusion}

It is evident from this study that prolonged use of Khat causes serious oral health issues including TMJD. This further emphasizes the threats of Khat chewing and is in addition to the previously published societal dangers such as a decline in productivity and intellectual backwardness among students. Khat use is a societal issue that needs to be addressed effectively at all levels.

\section{Recommendations}

Its recommended that governments should apply preventive programs to illustrate the dangers and bad sequalae of Khat abuse. The governments should provide incentives to farmers who produce alternative crops other than Khat (e.g. coffee beans). The governments should consider offering employment opportunities for the youth in order to reduce unemployment since the younger age groups represent the largest proportion of Khat users. In addition, laws should be imposed to fine, penalize and/or imprison producers, consumers, and traffickers to reduce and control Khat planting, abuse, and distribution.

\section{Funding}

This research received no specific grant from any funding agency in the public, commercial, or not-for-profit sectors.

\section{Acknowledgment}

The authors would like to thank the participants for accepting to participate in this study.

\section{References}

1. Balint EE, Falkay G, Balint GA. Khat-a controversial plant. Wiener Klinische Wochenschrift 2009; 121: 604-614.

2. Curto MA, Tembrock LR, Puppo P, Nogueira M, Simmons MP, Meimberg H. Evaluation of microsatellites of Catha edulis (khat; Celastraceae) identified using pyrosequencing. Biochem System Ecol 2013; 49: 1-9. 
3. Wabe NT. Chemistry, pharmacology, and toxicology of Khat (Catha Edulis Forsk): a review. Addict Health 2011; 3: 13 .

4. Date J, Tanida N, Hobara T. Khat chewing and pesticides: a study of adverse health effects in people of the mountainous areas of Yemen. Int J Env Health Res 2004; 14: 405-414.

5. Zahran MA, Khedr A, Dahmash A, El-Ameir YA. Khat farms in Yemen: Ecology, dangerous impacts and future promise. Egypt J Basic Appl Sci 2014; 1: 8.

6. Laswar AN, Darwish H. Prevalence of cigarette smoking and Khat chewing among Aden university medical students and their relationship to BP and body mass index. Saudi J Kidney Dis Transplant 2015; 20: 5.

7. AL-abed AAA, Sutan R, Al-Dubai SAR, Aljunid SM. Family context and khat chewing among adult Yemeni women: a cross-sectional study. Biomed Res Int 2014.

8. Mahfouz MS, Rahim BEEA, Solan YMH, Makeen AM, Alsanosy RM. Khat chewing habits in the population of the Jazan region, Saudi Arabia: prevalence and associated factors. Plos One 2015; 10.

9. Mahfouz MS, Alsanosy RM, Gaffar AM. The role of family background on adolescent khat chewing behavior in Jazan Region. Ann Gene Psych 2013; 12: 8.

10. Al-Sanosy RM. Pattern of khat abuse and academic performance among secondary school and college students in Jazan region, Kingdom of Saudi Arabia (KSA). J Fam Commun Med 2015; 16: 7.

11. Griffiths P, Gossop M, Wickenden S, Dunworth J, Harris K, Lloyd C. A transcultural pattern of drug use: Khat (khat) in the UK. Br J Psych 1997; 170: 281-284.

12. Kassim S, Croucher R, alAbsi M. Khat dependence syndrome: a cross sectional preliminary evaluation amongst UK-resident Yemeni Khat chewers. J Ethnopharmacol 2013; 146: 835-841.

13. Griffiths P, Gossop M, Wickenden S, Dunworth J, Harris K, Lloyd C. A transcultural pattern of drug use: khat (khat) in the UK. Br J Psych 1997; 170: 4.

14. Kassim S, Dalsania A, Nordgren J, Klein A, Hulbert J. Before the ban-an exploratory study of a local Khat market in East London, U.K. Harm Reduct J 2015; 12.

15. Almas K, Wazzan KA, Hussaini IA, Al-Ahdal KY, Khan NB. Temporomandibular joint status, occlusal attrition, cervical erosion and facial pain among substance abusers. OSTTDJ 2007; 30: 7.

16. El-Wajeh YAM, Thornhill MH. Khat and its health effects. Br Dent J 2009; 206: 17-21.
17. Yarom N, Epstein J, Levi H, Porat D, Kaufman E, Gorsky M. Oral manifestations of habitual khat chewing: a casecontrol study. Oral Surg Oral Med Oral Pathol Oral Radiol Endodontol 2010; 109: 60-66.

18. Damena T, Mossie A, Tesfaye M. Khat chewing and mental distress: a community based study, in Jimma City, Southwestern Ethiopia. List Ethiop J Health Sci 2011; 21.

19. Alem A, Kebede D, Kullgren G. The prevalence and socio-demographic correlates of Khat chewing in Butajira, Ethiopia. Acta Psychiatrica Scand 1999; 100: 840-891.

20. Ageely H. Health and socio-economic hazards associated with khat consumption. J Family Community Med 2008; 15: 3-11.

21. Khatib M, Jarrar Z, Bizrah M, Checinski K. Khat: social habit or cultural burden? A survey and review. J Ethn Subst Abuse 2013; 12: 140-153.

22. Abebe M, Kindie S and Adane K. Adverse health effects of Khat: a review. Fam Med Med Sci Res 2015; 4: 1.

23. Shariff M, Al-Moaleem M ,Al-Ahmari N. A multidisciplinary approach in the treatment of tempromandibular joint pain associated with Khat chewing. Case Rep Dentistry 2013.

24. Hill CM, Gibson A. The oral and dental effects of qat chewing. Oral Surg Oral Med Oral Pathol 1987; 63: 433-436.

25. National institute of dental and craniofacial research Prevalence of TMJD and its Signs and Symptoms. Access from https: //www.nidcr.nih.gov/research/data-statistics/ facial-pain/prevalence

26. Al Moaleem MM, Okshah AS, Al-Shahrani AA, Alshadidi AA, Shaabi FI, Mobark AH, Mattoo KA. Prevalence and severity of temporomandibular disorders among undergraduate medical students in association with Khat chewing. J Contemp Dent Pract 2017; 18: 23-28.

\section{*Correspondence to}

\section{Mansour Adam Mahmoud}

Clinical and Hospital Pharmacy Department

College of Pharmacy

Taibah University

Saudi Arabia 